\title{
Methodological model of chronic stress associated with ligature-induced periodontitis in rats: a radiographic study
}

\section{Alex Semenoff Segundo(a) Tereza Aparecida Delle Vedove Semenoff(a) \\ Álvaro Henrique Borges(a) Fábio Luis Miranda Pedro(a) Vivien Thiemy Sakai ${ }^{(a)}$}

(a) School of Dentistry of University of Cuiabá, Cuiabá, MT, Brazil.

Corresponding author:

Alex Semenoff Segundo

Rua Professora Azélia de Melo, 318, ap. 63

Cuiabá - MT - Brazil

CEP: 78005-700

E-mail:semenoff@uol.com.br

Received for publication on Aug 02, 2010 Accepted for publication on Oct 14, 2010

\begin{abstract}
This study evaluated the time efficiency of stress associated with ligature-induced periodontitis in rats. Sixty adult Wistar rats, housed in temperature-controlled rooms and receiving water and food ad libitum, were randomly separated into stress $(\mathrm{n}=30)$ or control groups $(\mathrm{n}=30)$. All animals were anesthetized, and nylon ligatures were placed at the gingival margin level of the maxillary right second molars. After the induction of periodontitis, rats in the stress group were subjected to physical restraint for 12 hours daily. The animals were euthanized after 7, 15 and 30 days by anesthetic overdose (10 animals per group per period). The right hemimaxillae were stored in formalin solution for 48 hours. Parallel radiographic images of the hemimaxillae were taken and processed following standard procedures. Radiographic examination was performed by a blinded and previously calibrated investigator. Bone height level was measured, and data were submitted to analysis of variance and post hoc Bonferroni tests $(\mathrm{p}<0.05)$. Rats in the stress group had greater bone loss than those in the control group at 7 and 15 days post-induction $(\mathrm{p}<0.05)$. After 30 days, there was no statistically significant difference between the groups ( $p>0.05)$. Restraint stress modulates the short-term progression of periodontal disease in rats. Therefore, the 12-hour daily physical restraint stress model in rats applied for up to 15 days is suitable for the investigation of the combined effect of ligation and restraint stress on periodontal degradation.
\end{abstract}

Descriptors: Rats; Radiography; Periodontal Diseases; Stress, Physiological.

\section{Introduction}

Stress is an organic response of the hypothalamic-pituitary-adrenal (HPA) axis to chemical, physical and emotional stimuli. Researchers categorize stress into several phases that can lead to fast reactions with no major consequences or determine the collapse of vital organ systems (exhaustion phase). ${ }^{1,2}$

Studies on the relationship between stress and periodontal disease are not novel. Since the discovery of microorganisms as etiological agents of periodontal disease, it was suggested that stressed people were more likely to develop periodontal disease such as acute necrotizing ulcerative gingivitis. ${ }^{3-5}$ The concept of acute disease has changed over the past years, although relations to psychosocial and emotional issues remain. ${ }^{6}$ 
The 12-hour daily physical restraint stress model in rats associated with experimentally induced periodontal disease is well-documented.-10 Other models using a short period of stress have also been demonstrated to be good options. ${ }^{11-13}$ In an attempt to minimize animal suffering and research expenses, the aim of the present work was to generate a short-term animal model that would minimize the number of days of the stress condition in rats with ligature-induced periodontitis.

\section{Material and Methods}

The Ethics Committee of University General Hospital, University of Cuiabá approved the protocol for this study (protocol \#2010-044). Sixty male Wistar rats (Rattus novergicus) with an average initial weight of $348 \mathrm{~g}$ were selected. Animals were housed in $16 \times 40 \times 30 \mathrm{~cm}$ polyethylene cages (five rats per cage) under controlled environmental temperature conditions $\left(23^{\circ} \mathrm{C}\right)$ and relative humidity $(40 \%)$ and a 12 -hour light/dark cycle. Food and water were available ad libitum.

The rats were anesthetized by a $0.1-\mathrm{mL}$ intramuscular injection of ketamine hydrochloride (Dopalen, Agribrands, Saúde Animal, Paulínia, SP, Brazil), combined with $0.05 \mathrm{~mL}$ of xylazine hydrochloride (Rompun, Bayer, Saúde Animal, São Paulo, SP, Brazil), per $100 \mathrm{~g}$ of body weight. After the anesthesia, a 5-0 nylon thread ligature (Ethicon, Johnson \& Johnson, São Paulo, SP, Brazil) was placed around the maxillary second molar in a submarginal position to induce experimental periodontitis. ${ }^{14-17}$

Animals were randomly separated into a stress group $(\mathrm{n}=30)$ and a control group $(\mathrm{n}=30)$. One day after the induction of periodontitis, rats in the stress group were placed individually in ventilated plastic restraint tubes for 12 hours daily.

The rats from both groups were sacrificed after 7,15 , or 30 days by anesthetic overdose, and the maxillae were collected for radiographic analysis. After each induction period, 20 animals were sacrificed: 10 in the stress group and 10 in the control group.

Right and left hemimaxillae were fixed in $10 \%$ formalin solution for $48 \mathrm{~h}$. Radiographs were taken using a dental X-ray unit (Specto 70x, DabiAtlante,
Ribeirão Preto, SP, Brazil). To take the images, specimens were placed on the film (Kodak insight dental film, São Paulo, SP, Brazil), and the X-ray cone was set perpendicular to it. The distance between the cone and the specimens as well as the exposure time of $0.3 \mathrm{~s}$ were standardized based on a previous pilot study. A trained operator processed all radiographs using the same time and temperature.

Radiographs were projected on a white board using a slide projector (Kodak-Ektagraphic III, São Paulo, SP, Brazil) that provided a 15-fold magnification of the images. After the identification of the structures between the first and second molars, the teeth and interproximal bone crest were drawn on the board, as was a horizontal line between the cusp tips of both teeth. At the contact point between the molars, a vertical line perpendicular to the horizontal line was drawn. The distance between the bone crest and the horizontal line was determined using digital calipers (Paquímetro Digital, Mitsu, São Paulo, SP, Brazil) and recorded for further analysis and comparisons. A previously calibrated and blinded operator performed all the measurements. During the calibration process, the standard errors of the mean differences of the radiographic results were $0.002 \mathrm{~mm}$. The average maxillae sizes in the stress and control groups were $1.97 \mathrm{~mm}$ and $1.98 \mathrm{~mm}$, respectively. The standard error of the mean difference between the groups was $0.003 .{ }^{18}$

The statistical significance of differences in the measured values among groups was evaluated by one-way analysis of variance and post hoc Bonferroni tests. For individual comparisons, an independent t-test was used. A difference was considered statistically significant if $\mathrm{p}<0.05$.

\section{Results}

During hemimaxillae collection and storage, some samples from the stress and control groups were lost, thus reducing the number of samples per group and per period of evaluation (Table 1).

Table 1 shows the average radiographic bone loss measurements assessed in rats from the stress and control groups after 7, 15 and 30 days of the induction of periodontal disease. The measurements at 7 days post-induction were similar to those at 15 days 
Table 1 - Crestal bone loss, in mm, determined by linear measurements taken at the interproximal space between the first and second molars in radiographic analyses of rat hemimaxillae.

\begin{tabular}{c|c|c|c}
\hline Groups & 7 days & 15 days & 30 days \\
\hline Stress & $2.67 \pm 0.54 \mathrm{aA}(\mathrm{n}=8)$ & $2.55 \pm 0.54 \mathrm{aA}(\mathrm{n}=6)$ & $3.43 \pm 0.49 \mathrm{bA}(\mathrm{n}=8)$ \\
\hline Control & $2.18 \pm 0.22 \mathrm{aB}(\mathrm{n}=7)$ & $2.11 \pm 0.36 \mathrm{aB}(\mathrm{n}=9)$ & $3.37 \pm 0.60 \mathrm{bA}(\mathrm{n}=8)$ \\
\hline
\end{tabular}

Means followed by different lower case letters in the same row and capital letters in the same column differ statistically $(p<0.05)$.

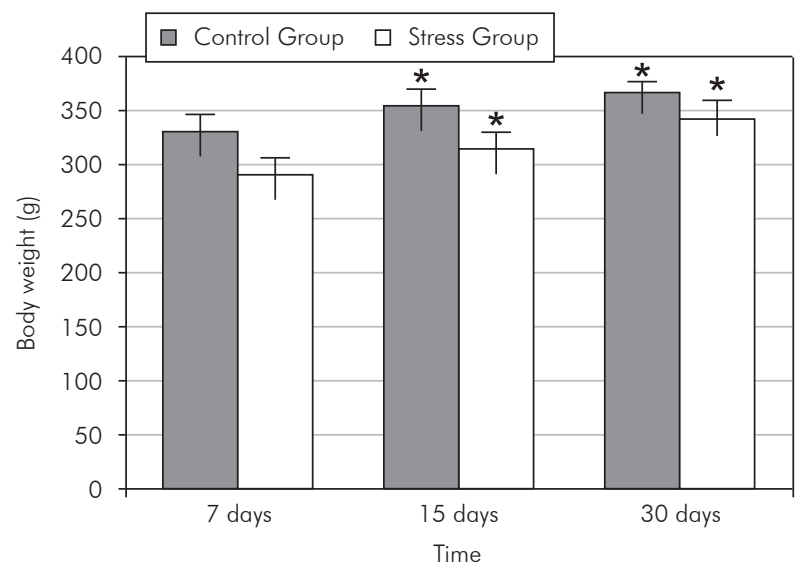

Figure 1 - Body weight, in grams, of rats after 7, 15 and 30 days of the induction of periodontal disease $\left({ }^{*} p<0.05\right)$.

in both the control and the stress groups ( $p>0.05)$. However, the values in these periods were statistically different from those at 30 days post-induction in both groups $(\mathrm{p}<0.05)$.

Greater bone losses were observed in the stress group when compared with the control group at 7 and 15 days $(\mathrm{p}<0.05)$. No statistically significant difference was observed between both groups at 30 days post-induction ( $\mathrm{p}>0.05)$.

Regarding the weight (Figure 1), there was no difference between the animals in the stress and control groups 7 days after the induction of periodontal disease $(\mathrm{p}>0.05)$. However, after 15 and 30 days, body weight loss was greater in rats in the stress group than in those of the control group $(\mathrm{p}<0.05)$.

\section{Discussion}

Studies using restraint stress and experimentally induced periodontitis models in rats are not recent $^{19-20}$ and were performed to provide important information about periodontal disease pathogenesis and progression. However, due to the difficulty in quantifying the amount and duration of stress, the detrimental effects of inadequate coping with stress and the possible adaptive response to stressors, several basic questions remain incompletely answered.

Many studies use the 12-hour daily physical restraint for 30 days, which certainly causes irreversible systemic changes in the organism, mainly in the HPA axis. ${ }^{7-10}$ However, the modulatory effect of stress on periodontal disease is controversial, and there is a search for factors that either have protective effects or impair the progression of the disease, irrespective of being induced or not. ${ }^{11-13}$

The present study demonstrated that restraint stress enhanced bone destruction in rats with ligature-induced periodontitis at 7 and 15 days post-induction, which is in agreement with other studies..$^{7-10}$ Chronic stress disrupts the body's internal balance, which was reflected by the animal weight at 15 and 30 days post-induction, ${ }^{9}$ and it impairs not only the ability of the immune system to relocate immune cells but also the ability of those cells to do their job of recognizing and responding to the pathogenic agent. ${ }^{21-23}$

However, a lack of significant differences between stress and control groups was found at 30 days. This result is unexpected and may be explained by a possible adaptive response to repeated stresses. The potential role of the daily repetition of the same physical restraint intervention in the dynamics of body homeostatic regulation remains to be elucidated, as this hypothesis was beyond the scope of this work.

In addition, despite the lack of statistically significant differences, another intriguing finding was the smaller values of bone loss at 15 days when compared with those at 7 days after the induction of periodontal disease both in the control and stress groups. A reasonable explanation for these data may 
be found in the small sample size, which occurred due to the loss of some hemimaxillae during collection and storage, mainly at 15 days post-induction in the stress group; this may be considered a weakness of the present work. It is well known that an adequate sample size with sufficient statistical power is required to yield reliable information.

As the size of the tooth crown might also represent a bias in our study because the occlusal plane was used as a reference for the measurements, we took care to assess the tooth size in both groups. However, no difference was found, and the measurements could be attributed solely to the destruc-

\section{References}

1. Selye $H$. The general adaptation syndrome and the diseases of adaptation. J Clin Endocrinol Metab. 1946;6(2):117-230.

2. Selye H. Stress and disease. Science 1955 Oct;122(3171):62531.

3. Barnes GP, Bowles WF, Carter HG. Acute necrotizing ulcerative gingivitis: a survey of 218 cases. J Periodontol. 1973 Jan;44(1):35-42.

4. Shannon IL, Kilgore WG, O'Leary TJ. Stress as a predisposing factor in necrotizing ulcerative gingivitis. J Periodontol. 1969 Apr;40(4):240-2.

5. Rowland RW. Necrotizing ulcerative gingivitis. Ann Periodontol. 1999 Dec;4(1):65-73.

6. Peruzzo DC, Benatti BB, Ambrosano GM, Nogueira-Filho GR, Sallum EA, Casati MZ, et al. A systematic review of stress and psychological factors as possible risk factors for periodontal disease. J Periodontol. 2007 Aug;78(8):1491-504.

7. Peruzzo DC, Benatti BB, Antunes IB, Andersen ML, Sallum EA, Casati MZ, et al. Chronic stress may modulate periodontaldisease: a study in rats. J Periodontol. 2008 Apr;79(4):697-704.

8. Nakajima K, Hamada N, Takahashi Y, Sasaguri K, Tsukinoki $\mathrm{K}$, Umemoto $\mathrm{T}$, et al. Restraint stress enhances alveolar bone loss in an experimental rat model. J Periodontol Res. 2006 Dec;41(6):527-34

9. Takada T, Yoshinari N, Sugiishi S, Kawase H, Yamane T, Noguchi T. Effect of restraint stress on the progression of experimental periodontitis in rats. J Periodontol. 2004 Feb;75(2):306-15.

10. Gaspersic R, Stiblar-Martincic D, Skaleric U. Influence of restraint stress on ligature-induced periodontitis in rats. Eur J Oral Sci. 2002 Apr;110(2):125-9.

11. Susin C, Rosing CK. Effect of variable moderate chronic stress on ligature-induced periodontal disease in Wistar rats. Acta Odontol Scand. 2003 Oct;61(5):273-7. tion of the crestal bone.

\section{Conclusion}

Taken together, our results allow us to conclude that restraint stress modulates the short term progression of periodontal disease in rats. Therefore, the 12-hour daily physical restraint stress model applied to rats for up to 15 days is suitable for investigating the combined effect of ligation and restraint stress on periodontal degradation. Further studies are necessary to clarify the mechanism involved in this process.

12. Semenoff-Segundo A, Hennemman C, Fontanela VRC, Rösing CK. The role of psychoneuroimmune interactions in the pathogenesis of ligature-induced periodontal disease in Wistar rats. J Int Acad Periodontol. 2007 Jan;9(1):26-31.

13. Semenoff-Segundo A, Semenoff TADV, Bosco AF, Biasoli ER, Ribeiro RV, Rocatto GEGD, et al. Efeito do estresse crônico na progressão de periodontite induzida por ligadura em ratos. Periodontia 2007 Set;17(3):62-66.

14. Semenoff TADV, Semenoff-Segundo A, Bosco AF, Nagata MJ, Garcia VG, Biasoli ER. Histometric analysis of ligatureinduced periodontitis in rats: a comparison of histological section planes. J Appl Oral Sci. 2008 Jul-Aug; 16(4):251-6.

15. Cavagni J, Soletti AC, Gaio EJ, Rosing CK. The effect of dexamethasone in the pathogenesis of ligature-induced-periodontal disease in Wistar rats. Braz Oral Res. 2005 OctDec;19(4):290-4.

16. Souza DM, Rocha RF. Low caloric value of ethanol itself increases alveolar bone loss in ligature-induced periodontitis in male rats. Bras Oral Res. 2009 Oct-Dez;23(4):460-6.

17. Fernandes MI, Gaio EJ, Oppermann RV, Rados PV, Rosing CK. Comparison of histometric and morphometric analyses of bone height in ligature-induced periodontitis in rats. Bras Oral Res. 2007 Jul-Sep; 21(3):216-21.

18. Semenoff-Segundo A, Semenoff TADV, Biasoli ER. Efeito da ingestão crônica de álcool na progressão de periodontite induzida em ratos da linhagem Fischer-344. RGO. 2009 JanMar;57(1):87-91.

19. Carranza FA Jr, Simes RJ, Mayo J, Cabrini RL. Histometric evaluation of periodontal bone loss in rats. I. The effect of marginal irritation, systemic irradiation and trauma from occlusion. J Periodontal Res. 1971;6(1):65-72.

20. Carranza FA Jr, Simes RJ, Cabrine RL. Effect of combined etiologic factors in experimental periodontal lesions. J Periodontal Res Suppl. 1969;4:33-4. 
21. Dragos D, Tanasescu MD. The effect of stress on the defense systems. J Med Life. 2010 Jan-Mar;3(1):10-8.

22. Dhabhar FS. Enhancing versus suppressive effects of stress on immune function: implications for immunoprotection versus immunopathology. Allergy Asthma Clin Immunol. 2008 Mar;4(1):2-11.
23. Dhabhar FS. Enhancing versus suppressive effects of stress on immune function: implications for immunoprotection and immunopathology Neuroimmunomodulation. 2009 Jun;16(5):300-17. 